\title{
EDITORIAL
}

\section{The Meiji Centenary Number}

THIs issue marks the completion of the second volume of Modern Asian Studies and, unlike its seven predecessors, is devoted exclusively to a single country. In the formulation of the editorial policy of our journal it was agreed from the outset that we should try to avoid over concentration on any part of the Asian area with which it is concerned, and indeed should normally try to make each issue as widely representative as possible. But it was also agreed that from time to time special numbers should be devoted exclusively to a single country or theme, and the occasion of the centenary of the Meiji Restoration, to be celebrated in Japan on 23 October 1968, affords an obvious opportunity for putting this intention into practice for the first time.

By any standards the transformation of Japan, formally initiated one hundred years ago, provides one of the dominant themes which can never be wholly ignored by any student of modern Asia, whatever may be his own particular region or discipline. It is for this reason, and not because of any facile assumption that a single issue of a new journal can hope to make any revolutionary contribution to the understanding of one of the most remarkable developments in human history, that we have thought it fitting to offer our readers four articles, one by a Japanese, one by an American, and two by British scholars which, from the varied standpoints of four of the social sciences, may nevertheless add something to our appreciation of Japan's decisive century. 